\title{
Detecção de ácido ocadaico em mexilhões Perna perna (LINNÈ, 1758) cultivados em fazenda de maricultura na baía de Ilha Grande, Angra dos Reis, RJ
}

\author{
Detection of okadaic acid in mussels Perna perna (LINNÈ, 1758) \\ harvesting in mariculture farm, llha Grande, Angra dos Reis, RJ
}

\author{
Aderbson J. Lourenço, ${ }^{*}$ Vanessa de M. Ferreira, ${ }^{* \star}$ Pedro Paulo de O. da Silva, ${ }^{* \star *}$ Carlos A. da R. Rosa, ${ }^{* \star \star \star}$ \\ Glória M. Direito, ${ }^{* \star * \star *}$ Gesilene M. de Oliveira, ${ }^{* \star * \star * \star}$ Alexandre da S. de Miranda ${ }^{\star * \star * \star * *}$
}

\begin{abstract}
Resumo
Este trabalho foi realizado na fazenda de maricultura localizada na enseada de Maciéis, baía de llha Grande (Angra dos Reis, RJ). No outono de 2004, mexilhões (Perna perna) foram coletados para detectar a presença da ficotoxina ácido ocadaico (AO). Esta toxina pode ser produzida por algumas espécies de dinoflagelados pertencentes aos gêneros Prorocentrum e Dinophysis. Os mexilhões, ao se alimentarem destas microalgas, acumulam a toxina, principalmente em sua glândula digestiva (hepatopâncreas), desencadeando no ser humano a síndrome do Envenenamento Diarréico por Moluscos (EDM). A ficotoxina AO é o principal responsável pela síndrome EDM, que é caracterizada por náuseas, dores abdominais, vômitos e diarréia, se

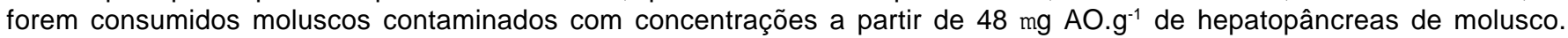
Glândulas digestivas dos mexilhões coletados foram homogeneizadas para extração e detecção de AO. As amostras foram analisadas por Cromatografia Líquida de Alta Eficiência com Detecção Fluorescência (CLAE-DF). Os resultados cromatográficos indicaram a presença da toxina $\mathrm{AO}$, em baixa concentração ( 2ng AO. $\mathrm{g}^{-1}$ hepatopâncreas de molusco), em apenas uma das amostras da primeira coleta (março/2004) e sua ausência nas coletas posteriores (abril e maio/2004).
\end{abstract}

Palavras-chave: cultivo de mexilhão, baía de llha Grande, ácido ocadaico.

\begin{abstract}
This work was conducted at the Sea Culture Farm at Maciéis bay, llha Grande Bay (Angra dos Reis-RJ). During the autumn of 2004, mussels (Perna perna) were collected from the cultivation area and were analyzed to verify the presence of the phycotoxin okadaic acid (OA). This toxin is produced by dinoflagellates of the genders Prorocentrum and Dinophysis. Mussels that eat these microalgae accumulate the toxin in their flesh, mainly in their hepatopancreas. The ingestion of these mussels by humans can bring about the Diarrhetic Shellfish Poisoning (DSP) syndrome in human being. The toxin (OA) is the main responsible for the DSP syndrome, which is characterized by nausea, stomachache, vomits and diarrhea, if mussels containing over $48 \mu \mathrm{g}$ of $\mathrm{OA}$ per gram of hepatopancreas are consumed. The mussels digestive glands were homogenized for the extraction and derivatization of the diarrheic phycotoxin. The samples were analyzed by High Performance Liquid Chromatography with Fluriometric Detection (HPLC-FD). The chromatographic results indicated the presence of the OA toxin in low concentration ( 2ng OA per mussel hepatopancreas grams) in only one of the samples from the first collection (March/2004) and its absence in the following collections (April and May/2004).
\end{abstract}

Keywords: mussel cultivation, Ilha Grande Bay, okadaic acid.

\section{Introdução}

Os oceanos, através dos sistemas de cultivo ou, simplesmente, pela extração direta, constituem uma importante fonte de alimento para o Homem. Nos últimos anos foi observada uma diminuição da contribuição da pesca ao suprimento de alimentos de origem marinha, enquanto os provenientes da aqüicultura aumentam. Excluindo a China, devido à não-confiabilidade dos dados reportados, os suprimentos provindos da aqüicultura, para o mundo como um todo, cresceram de 1,6 kg per capita para 2,12 kg em

*Biólogo, mestre.

**Oceanógrafa, mestre, professora substituta - Instituto de Biologia, UFRRJ.

${ }^{* * *}$ Médico-veterinário, doutor, professor adjunto - Instituto de Tecnologia de Alimentos, UFRRJ.

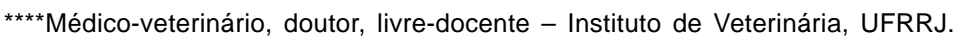

*****Médica-veterinária, doutora, professora adjunta - Instituto de Veterinária, UFRRJ.

$* * * * *$ Zootecnista, mestre.

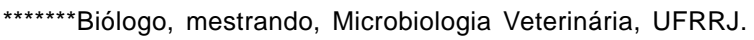


1998. E cerca de $44 \%$ da maricultura mundial é centralizada no cultivo de moluscos filtradores (FAO, 2002).

Segundo o Ibama (2002), a produção da aqüicultura nacional (água doce e salgada) foi de 176530,5t em 2000, com um crescimento de 190,8\% em relação a 1996 (607000 t). Deste montante, o cultivo de mexilhões contribuiu (em toneladas) com 11760, ostras com 1190 e vieiras 0,5. A baía de Ilha Grande vem se tornando, desde 1995, um pólo de desenvolvimento na maricultura de moluscos bivalvos. Atualmente 20 fazendas estão em funcionamento e mais sete em fase de implantação. São cultivados os moluscos bivalvos: mexilhão (Perna perna), ostra (Crassostrea gigas) e vieiras (Nodipecten nodosus). Os parques de cultivo na Ilha Grande produziram, no ano de 2002, 20 toneladas de mexilhão, 5000 dúzias de vieiras e 1000 dúzias de ostras. *

Mexilhões alimentam-se, através de filtração, do fitoplâncton presente na coluna d'água. $\mathrm{O}$ fitoplâncton é uma comunidade constituída por diversos grupos de microalgas, entre elas dinoflagelados pertencentes aos gêneros Prorocentrum e Dinophysis, potencialmente capazes de produzir toxinas diarréicas implicadas no Envenenamento Diarréico por Moluscos (Yasumoto e Murata, 1993). O ácido ocadaico $(\mathrm{AO})$ é a principal toxina diarréica e já foi detectada na baía de Sepetiba (Oliveira, 2001; Ferreira, 2004) e em moluscos cultivados no litoral de Santa Catarina (Proença et al., 1998).

O mecanismo de ação do ácido ocadaico não está completamente elucidado. A nível molecular, sabe-se que as proteínas fosfatase $1 \mathrm{e}$ 2A são inibidas pelo ácido ocadaico (Bialojam e Takai, 1988). A inibição da ação dessas proteínas também tem sido relacionada com a inflamação do intestino e produção de diarréia (Hamano et al., 1986; Terao et al., 1986; Cohen et al., 1990). Estudos têm demonstrado que o ácido ocadaico além de causar distúrbios gastrointestinais apresenta uma potente capacidade de promover tumores no sistema digestório, quando consumidas regularmente (Daranas et al., 2001).

O envenenamento diarréico por moluscos pode ser caracterizado, em evento agudo, com ingestão de doses acima de $48 \mu \mathrm{g}$ (LOAEL)

(Van Egmond et al., 1992 apud Vieytes et al., 1997); os sintomas são náuseas, dores abdominais, vômitos e diarréia. Surgem no intervalo entre 30 minutos até poucas horas após o consumo de moluscos contaminados. Raramente o quadro clínico manifesta-se passadas mais de 12 horas. Os sintomas cessam após três dias, com ou sem tratamento médico (Yassumoto et al., 1980).

\footnotetext{
* Comunicação pessoal. Biólogo MSc Fernando Vitor de Abreu Moschen, da Secretaria de Agricultura e Pesca da Prefeitura Municipal de Angra dos Reis.
}

O presente estudo teve por objetivo detectar e quantificar a ficotoxina ácido ocadaico em mexilhões cultivados na enseada de Maciéis.

\section{Material e métodos}

\section{Área de estudos}

A enseada de Maciéis localiza-se na baía de Ilha Grande, no município de Angra dos Reis, litoral sul do estado do Rio de Janeiro (Figura 1). Juntamente com a baía de Sepetiba, ambas funcionam como um sistema estuarino parcialmente misturado (Signorini, 1980).
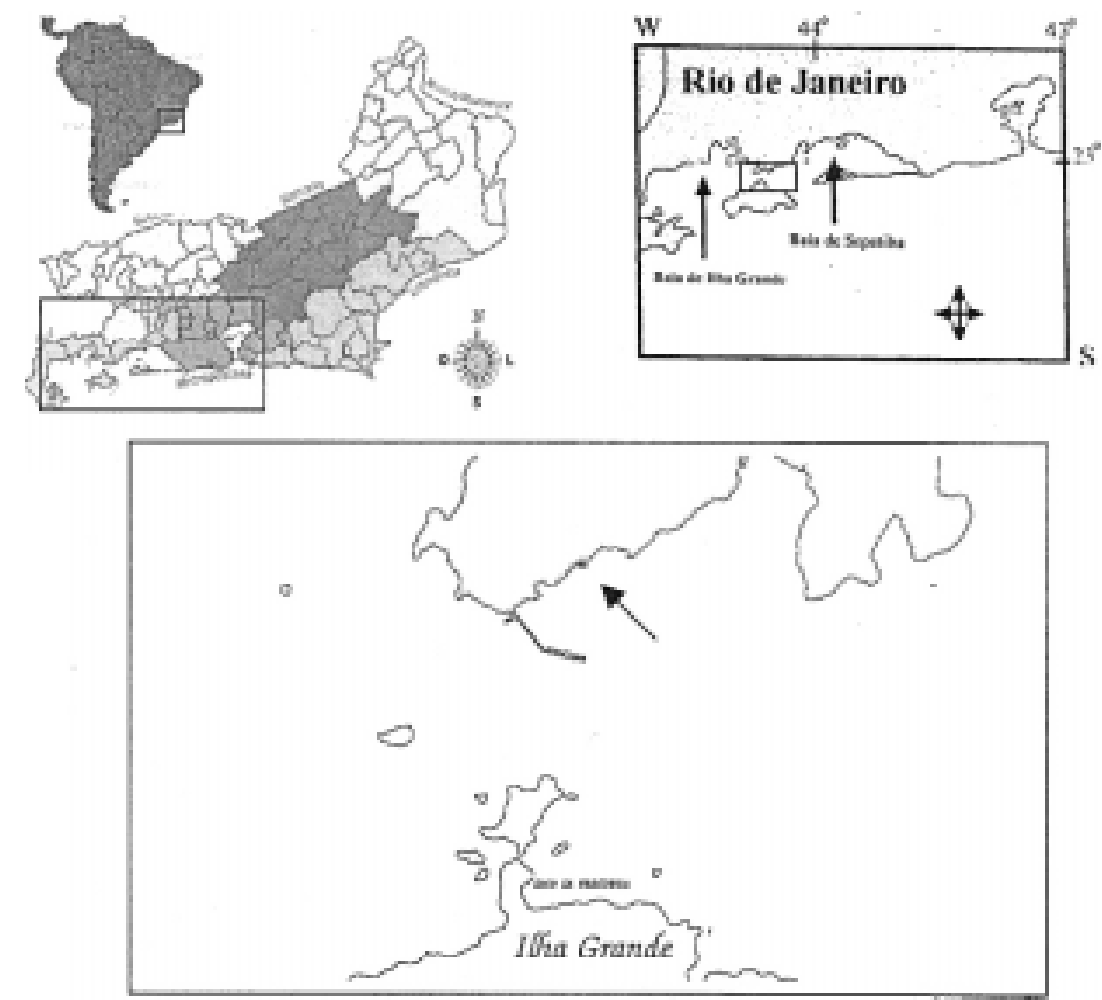

Figura 1: Mapa da baía de Ilha Grande (referência 1) localização Fazenda Marinha Boa Vista de Maciéis - (Coordenada geográfica do centro do cultivo $23^{\circ} 03^{\prime} 03^{\prime \prime} \mathrm{S}$ (440 13'33,9" W)

\section{Amostragem}

Os mexilhões foram coletados em três pontos diferentes da fazenda na proporção de 50 indivíduos adultos por coleta (para garantir a representatividade estatística), na faixa de tamanho utilizada para comercialização, ou seja, maiores que $6 \mathrm{~cm}$ (Avelar, 1998).

\section{Extração da ficotoxina $A O$}

O ácido ocadaico foi extraído segundo o procedimento descrito por Sigma (1993). A ficotoxina AO foi extraída da matriz orgânica do hepatopâncreas dos moluscos com metanol aquoso. Em seguida o extrato metanólico passou por etapas de limpeza que utilizaram éter de petróleo e clorofórmio. Essa última fase foi evaporada a $60^{\circ} \mathrm{C}$ e sob fluxo de nitrogênio. O resíduo foi redissolvido em acetonitrila. 
Como a molécula do $\mathrm{AO}$ não fluoresce naturalmente, para ser detectada necessitou passar pelo processo de derivação onde um cromóforo (1-(bromoacetil)pireno) foi acrescentado na porção carboxílica da molécula da ficotoxina. Tal procedimento foi otimizado por Silva (2001).

\section{Identificação e quantificação do $A O$}

Alíquotas de $20 \mu \mathrm{l}$ da solução derivada foram injetadas no sistema de Cromatografia Líquida de Alta Eficiência (Waters Associats, inc, Miliford, M.A - USA) equipado com detector de fluorescência Waters (modelo 420) com excitação 333nm e emissão 440nm. Utilizou-se injetor Reodyne, com "loop" de $20 \mu \mathrm{l}$. Os dados obtidos foram analisados pelo integrador registrador Waters Data Module (modelo 740). As condições cromatográficas utilizadas foram: fase móvel com acetonitrila e água ultrapura $(85: 15 \mathrm{v} / \mathrm{v})$; fluxo de $1 \mathrm{ml}^{\text {.minuto-1; coluna }}$ cromatográfica Microsorb C18 (4,6 X $15 \mathrm{~mm}$ ) Microsorb-VM ${ }^{\mathrm{TM}}$ $10 \mu \mathrm{m}$ (Varian-USA), a temperatura ambiente.

\section{Resultados e discussão}

Para que a toxina presente nas amostras pudesse ser identificada, primeiramente foram realizadas injeções com o padrão da toxina ácido ocadaico. Através do tempo de retenção médio (16,524 minutos) encontrado o pico correspondente ao $\mathrm{AO}$ foi identificado (Figura 2). E para posterior cálculo das concentrações de toxina foi utilizada a área média $(88263,80)$ gerada pelo padrão (Tabela 1).

Tabela 1: Tempo de retenção (em minutos) e área do padrão do AO em sistema CLAE-DF, utilizando coluna C18 e fase móvel acetonitrila: água ultrapura, na proporção 85:15 (v/v).

\begin{tabular}{lcc}
\hline \multicolumn{1}{c}{ Data } & Tempo de retenção & Área \\
\hline \multicolumn{1}{c}{ 26/jun } & 16,150 & 148434 \\
& 16,571 & 80890 \\
& 16,665 & 76240 \\
& 16,601 & 42996 \\
& 16,631 & 92759 \\
\hline Média & $\mathbf{1 6 , 5 2 4}$ & $\mathbf{8 8 2 6 3 , 8 0}$ \\
Desvio-padrão & $\mathbf{0 , 2 1}$ & $\mathbf{3 8 3 6 9 , 1 9}$ \\
\hline
\end{tabular}

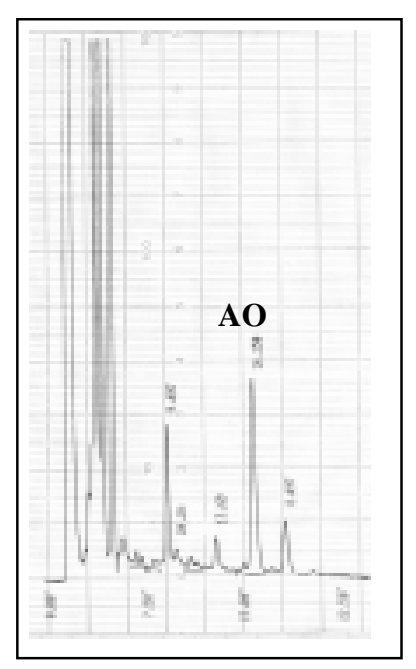

Figura 2: Cromatograma do padrão ácido ocadaico com tempo de retenção 16,150 e área de 148434 .
Foram realizadas três coletas no outono de 2004 (março, abril e maio), com três amostragens de mexilhões cada. A ficotoxina ácido ocadaico foi detectada, com concentração de 2,65 $\mathrm{ngAO} \cdot \mathrm{g}^{-1}$ de hepatopâncreas de molusco, em apenas uma amostra das três coletadas no mês de março (Figura 3: cromatograma A). Para que a identidade da toxina fosse confirmada, foi realizada uma coinjeção com o padrão (Figura 3: cromatograma B).

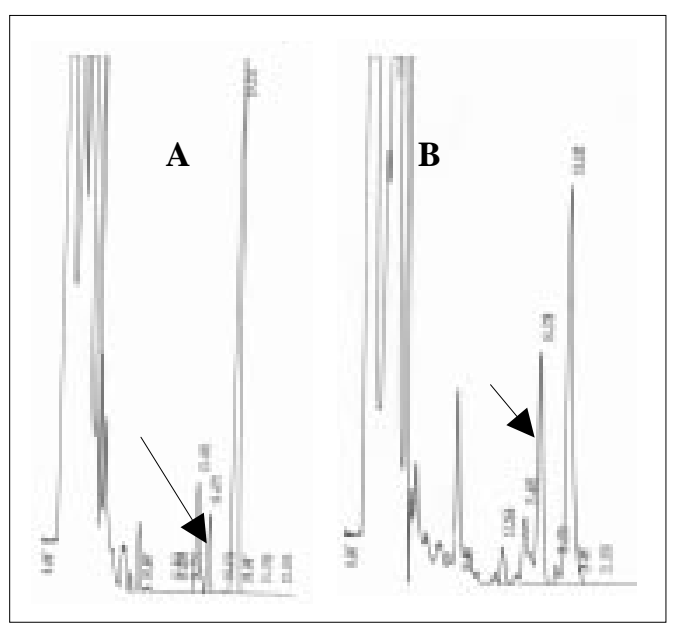

Figura 3: Cromatograma da amostra 1 da primeira coleta realizada na enseada de Maciéis. A) cromatograma da amostra com a presença da toxina com tempo de retenção de 16,675 e área de 43711 e B) da coinjeção com tempo de retenção de 16,728 e área de 65698 .

Esta concentração encontra-se uma ordem de grandeza abaixo do limite inferior aceito por países como Japão e Canadá, que adotam níveis inferiores a 2,0 mg AO.g-1 de hepatopâncreas de molusco para a comercialização e o consumo desses bivalvos (Andersen, 1996). Dessa forma, os mexilhões cultivados em Maciés estariam aptos ao consumo humano, segundo as normas supracitadas. Em nosso país, no entanto, ainda não existe nenhum tipo de normatização em relação às toxinas produzidas por microalgas.

A ficotoxina $A O$ também foi detectada, em mexilhões obtidos de bancos naturais, na baía de Sepetiba, litoral do Rio de Janeiro, em concentrações da mesma ordem de grandeza (nanogramas) encontradas pelo presente trabalho (Oliveira, 2001 e Ferreira, 2004). Proença (1998), em mexilhões cultivados no litoral de Santa Catarina, detectou a mesma ficotoxina $\mathrm{AO}$ em concentrações uma ordem de grandeza maior (microgramas), muito próximas dos limites aceitos internacionalmente para a comercialização de moluscos.

Os mexilhões analisados das coletas de abril e maio não apresentaram a presença da ficotoxina ácido ocadaico (Figura 4: Cromatograma A). A ausência da ficotoxina foi confirmada com a realização da coinjeção (Figura 4: Cromatograma B) onde detectou-se o $\mathrm{AO}$ oriundo do padrão que foi injetado juntamente com a amostra. 


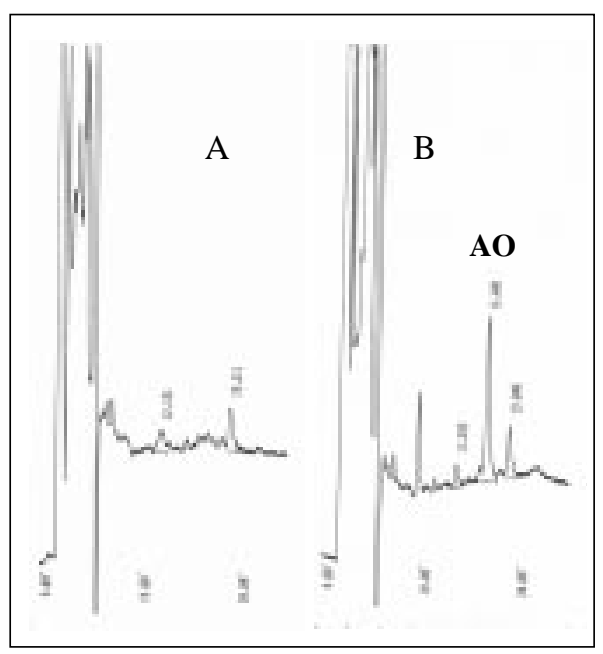

Figura 4: Cromatograma da amostra 3 da segunda coleta realizada na enseada de Maciéis. A) cromatograma da amostra sem a presença da toxina e B) da coinjeção com tempo de retenção de 16,601 e área de 42996.

\section{Referências}

ANDERSEN, P. Design and Implementation of some Harmful Algal Monitoring Systems. IOC Technical Series nํ 44, UNESCO, 1996.

AVELAR, J. C. L. Manual de Mitilicultura. Ministério do Meio Ambiente/ Plano Nacional de Meio Ambiente/Plano de Execução Descentralizada. Brasília, DF, 1998.

BIALOJAN, C., TAKAI, A. Inhibitory effect of a marine-sponge toxin, okadaic acid, on protein phosphatases. Specificity and kinetics Biochem. J., v. 256, 1988. p. 283-290.

COHEN, P., HOLMES, C. F. B. \& TSUKITANI, Y. Okadaic acid: a new probe for the study of cellular regulation. Trends Biochem. Sci., v.15, 1990. p. 98-102.

DARANAS, A. H., NORTE, M., FERNANDEZ, J. J. Toxic Marine Microalgae. Toxicon, v. 39, 2001. p. 1101-1132.

FAO- FOOD AND AGRICULTURE ORGANIZATION DF THE UNITED NATIONS. Part 1: World review of fisheries and aquaculture. In: FAO. The state of world fisheries and aquaculture. Editorial Group FAO. 2002. p. 3-54.

FERREIRA, V. M. Detecção de ácido ocadaico produzidos por Dinophysis spp. (Ehremberg, 1839), em mexilhões Perna perna, (Linnè, 1858), em situação de primavera e verão, nas ilhas Guaíba e Madeira, baía de Sepetiba, Rio de Janeiro. 2004. 54 f. Tese (Mestrado) - Pósgraduação em Microbiologia Veterinária, Universidade Federal Rural do Rio de Janeiro, 2004.

HAMANO, Y., Y. KINOSHITA, T. YASUMOT, Enteropathogenity of diarrhetic shellfísh toxins in intestinal models. J. Food Hyg. Soc. Jpn. v. 27, 1986. p. 375-379.

IBAMA. Capítulo 2: O estado dos recursos pesqueiros - Pesca extrativista e aqüicultura. In: SANTOS, T. C. C., CÂMARA, J. B. D. (Organizadores) GEOBRASIL - Perspectivas do meio ambiente no Brasil. Editora IBAMA, Brasília, DF, 2002, p. 132-147.

\section{Conclusão}

O ácido ocadaico foi detectado em apenas uma das três amostras coletadas no mês de março de 2004. Porém, embora a ficotoxina tenha sido detectada, as concentrações encontradas estiveram abaixo do necessário para o desencadeamento da síndrome EDM. Os mexilhões coletados nos meses de abril e maio não apresentaram a presença da ficotoxina $\mathrm{AO}$.

Portanto, os mexilhões cultivados na enseada de Maciés encontravam-se aptos ao consumo humano, durante 0 período analisado, se consideradas as normas para ficotoxinas diarréicas aceitas internacionalmente para a comercialização de moluscos. Ainda não existem no Brasil tais normas para a produção e consumo de moluscos.

Salienta-se a necessidade imperativa de que sejam intensificadas as pesquisas nesse âmbito (monitoramento das fazendas) para que se assegure tanto a sanidade dos moluscos quanto a proteção à saúde pública.

OLIVEIRA, G. M. Detecção do ácido ocadaico por cromatografia líquida de alta eficiência em mariscos (Perna perna) capturados na baía de Sepetiba. 2001. 85 f. Tese (Mestrado) - Instituto de Tecnologia de Alimentos - Universidade Federal Rural do Rio de Janeiro, 2001.

PROENÇA, L. A., SCHIMITT, F., COSTA, T \& RÖRIG, L. R. Just a diarrhea? Evidence of diarrhetic shellfísh poisoning in Santa Catarina, Brazil. Journal of the Brazilian Association for the Advancement of Science. v. 50, n 6 November/December, 1998. p. 458- 462.

SIGNORINI, L.C. A Study of the Circulation in Bay of Ilha Grande and of Sepetiba. Part I. A Survey of the Circulation based on Experimental Field Data. Bol. Inst. Oceonogr. S Paulo. Instituto Oceanográfico da Universidade de São Paulo. 1980. p. 15-21.

SILVA, P. P. O. Otimização de metodologia para detecção de ácido ocadaico por cromatografia líquida de alta eficiência em moluscos bivalvos. 2001. 62 f. Tese (Doutorado) - Pós-graduação em Ciências Veterinárias - Universidade Federal Rural do Rio de Janeiro, 2001.

SIGMA CHEMICAL CO., St. Louis - USA - 1993.

TERAO, K., ITO, E., OHKUSU, M., YASUMOTO, T. Histophatological studies on experimental marine toxin poisoning. I. Ultrastructural changes in the small intestine and liver of suckling mice induced by dinophysistoxin 1 and pectonotoxin 1. Toxicon. v. 24. 1986. p. 11411151.

VIEYTES, M. R., FONTAL, O. I., LEIRA, F., BAPTISTA DE SOUZA, J. M. V., BOTANA, L. M. A Fluorescent microplate assay for diarrhetic shellfish toxins. Analytical Biochemistry. v. 248, 1997. p. 258-264.

YASUMOTO, T., OSHIMA, Y., SUGAWARA, W., FUKUYO, Y., OGURI, H., IGARASHI, T., FUJITA, N. Identification of Dinophysis fortii as the causative organism of diarrhetic shellfish poisoning. Bulletin of the Japanese Society of Scientific Fisheries. v. 46, 1980. p. 14051411.

YASUMOTO, T., MURATA, M. Marine toxins. Chem. Rev. v. 93, 1993. p. 1897-1909. 